\title{
A IMPLANTAÇÃO DO REUNI NA UFF: AMPLIAÇÃO DE DIREITOS OU PRECARIZAÇÃO DO ENSINO SUPERIOR?
}

DOI: $10.5902 / 2318133831483$

\author{
Renata Maldonado da Silva \\ Micheli Marques Borowsky \\ Universidade Estadual do Norte Fluminense Darcy Ribeiro, Brasil.
}

\begin{abstract}
Resumo
Neste texto discute-se elementos presentes nas transformações do ensino superior no Brasil, no contexto das modificações no modo de produção capitalista, a partir da década de 1970. Nesse novo contexto, o ensino superior foi reestruturado e passou pelos efeitos do ideário neoliberal e, consequentemente, havendo maior aproximação com os princípios do mercado. Dentre as principais mudanças nesse âmbito do ensino, o artigo terá como foco de análise a elaboração do Programa de Apoio a Planos de Reestruturação e Expansão das Universidades Federais - Reuni implantado pelo Plano de Desenvolvimento da Educação - PDE - em 2007. O Reuni tinha como objetivos principais ampliar o acesso ao ensino superior nas universidades federais, mediante a ampliação dos campi, dos novos cursos presenciais, principalmente noturnos, aumentando a oferta de vagas e a reestruturação curricular dos cursos de graduação e pós-graduação.

Palavras-chave: educação superior; Reuni; UFF.
\end{abstract}

\section{THE IMPLEMENTATION OF REUNI IN THE UFF: EXTENSION OF RIGHTS OR PRECARIOUSNESS OF HIGHER EDUCATION?}

\section{Abstract}

This article aims to discuss some elements present in the transformations of higher education in Brazil, in the context of changes in the capitalist mode of production, from the 1970s. In this new context, higher education is restructured and has suffered the effects of the ideology neoliberal and, consequently, closer approximation to market principles. Among the main changes in this field of education, the article will focus on the elaboration of the Federal University Restructuring and Expansion Plans Support Program - Reuni -, implemented by the Education Development Plan PDE - in 2007. The Reuni's main objectives were to expand access to higher education in federal universities by expanding campuses, new in-person courses, mainly at night, increasing vacancies and curricular restructuring of undergraduate and postgraduate courses.

Keywords: higher education; Reuni; UFF. 


\section{Introdução}

1 partir do pós-guerra houve um fortalecimento e expansionismo do modelo $\triangle$ fordista-keynesiano na economia mundial, por meio do Estado Uintervencionista, segundo Harvey (2008). Este Estado cumpriu - até o momento em que o modelo econômico deu sinais de desgaste - a função de conciliador de classes: enquanto investiu em políticas sociais para a classe trabalhadora, como saúde, educação e habitação, ao mesmo tempo em que não deixou de atender às demandas do capital. Segundo Hobsbawn (1995), que denominou esse período de Era de Ouro, foi um momento de intensa prosperidade econômica, sob a hegemonia norteamericana, no qual ocorreu uma espécie de "casamento entre o liberalismo econômico e a democracia social" (p. 264). Entretanto, o mesmo autor ressaltou que somente uma parcela da população mundial teve acesso aos benefícios desse boom econômico, pois os países do chamado Terceiro Mundo mantiveram os mesmos índices de pobreza e desigualdade social intervencionista.

Contudo, a partir da década de. 1970, o modelo fordista-keynesiano começou a dar sinais de esgotamento, já sinalizando a grande crise de acumulação do capital que iria ocorrer nos próximos anos. Um desses indícios foi o fim do acordo Bretton Woods, em agosto de 1971. Diante da crescente demanda mundial por ouro, Richard Nixon, presidente dos EUA, cancelou a conversibilidade direta do dólar em ouro gerando a desvalorização da moeda americana, o que impactou todo o sistema monetário internacional.

Harvey (2008) chamou a atenção de que o liberalismo mundial já perdia sua força e a década de 1970 foi marcada por uma forte recessão econômica, aliada às altas taxas de desemprego e às reduzidas taxas de arrecadação de impostos. Em função disso, alguns países da Europa assistiram a ruína de suas indústrias tradicionais na área siderúrgica, metalúrgica, têxteis, automobilística e o setor dos transportes aéreos. A produção industrial diminuiu e aumentou o preço dos produtos para os consumidores, gerando acentuada alta inflacionária.

Neste contexto, soma-se a descoberta, pelos países do Oriente Médio, de que o petróleo é um bem não renovável e chegaria ao seu fim. Com isso a Opep decidiu aumentar o preço do produto. Para ter dimensão do impacto econômico causado na época, o preço do barril que em outubro de 1973 custava US\$2,90, em janeiro de 1974 chegou a US\$11,65, um aumento de $400 \%$ em apenas três meses.

Simultaneamente, buscando resgatar o período em que o Estado atuou como regulador do conflito capital versus trabalho, Harvey (2008) apontou a neoliberalização como "um projeto utópico de restabelecimento das condições de acumulação do poder do capital e de restauração do poder das elites econômicas" (p. 27). Portanto, a partir da crise da década de 1970, a teoria neoliberal passou a ter influência em vários campos políticos, buscando responder ao grave processo de estagflação que vinha ocorrendo na década de 1970. Portanto, surgiu o discurso de que o Estado havia atuado excessivamente na sociedade, sobretudo, no âmbito dos direitos sociais. 
Conforme o mesmo autor acima citado apontou, a crise econômica de 1973 pôs em xeque o regime de acumulação fordista. Portanto, até meados dos anos 1980 houve um período de reorganização na produção econômica, social e política dos países capitalistas avançados e periféricos. Além disso, Harvey (2008) considerou que "a crise do fordismo foi tanto geográfica e geopolítica como uma crise de endividamento, luta de classes ou estagnação corporativa das nações" (p. 174).

A partir dessa afirmação, compreende-se que se tentou resolver o problema da superacumulação por meio do deslocamento geográfico - criou-se novos centros de acumulação como a Europa Ocidental, Japão e América Latina - e pela formação do capital fictício. Um novo regime de acumulação estava sendo formado envolvendo "educação, flexibilidade e mobilidade geográfica", que foi denominado pelo autor de "acumulação flexível" (Harvey, 2008, p. 175).

O regime de acumulação flexível baseou-se na reorganização das relações produtivas, ou seja, em novas formas de produção e trabalho, em resposta à crise do sistema capitalista, agora com mais flexibilidade e mobilidade (Harvey, 2008). A flexibilidade no mercado de trabalho transformou completamente as relações entre a burguesia e as forças produtivas, bem como a função do Estado nesse processo organizacional. Os regimes de trabalho, antes rígidos, mecânicos e disciplinadores, passaram a ser mais flexíveis, devido à redução do emprego regular. A partir de agora, a produção e o consumo não são eram mais em massa e, sim, conforme a demanda do mercado, com produtos em escala limitada. Nesse contexto, a burguesia aproveitou do enfraquecimento da organização sindical e do excedente de mão de obra desempregada, para contratar trabalhadores por meio de contratos temporários, retirando seus direitos trabalhistas como pagamento de férias, décimo terceiro e previdência, no momento que não registravam os trabalhadores.

Para Harvey (2008, p. 144), "a atual tendência dos mercados de trabalho foi a de reduzir o número de trabalhadores 'centrais' e empregar cada vez mais uma força de trabalho que entra facilmente e é demitida sem custos quando as coisas ficam ruins". A pretensão da nova acumulação é substituir o empregado permanente pelos trabalhadores flexíveis, pois os direitos trabalhistas conquistados no liberalismo embutido (Harvey, 2014), como carteira assinada, fundo de garantia, décimo terceiro, férias, entre outros, foram substituídos por contratos por tempo determinado.

De acordo com Lima (2007), as estratégias elaboradas pela burguesia internacional para superar as crises dos anos 1970, exigiu um "reordenamento do papel dos Estados e um novo projeto burguês de sociabilidade" (p. 21). Portanto, a partir das transformações do capitalismo de acumulação monopolista para a mundialização do capital financeiro e rentista, novas formas de organização do trabalho, de gestão e uso das novas tecnologias são exigidas em prol da produtividade e do lucro das empresas (Mancebo et al, 2016). A partir disso, buscando atender às demandas do capital financeiro é necessário (re) pensar o sistema político dos países periféricos, mais vulneráveis nesse novo modelo e aplicar reformas para que o Estado possa investir mais no mercado financeiro internacional (Lima, 2007). 
Nesse contexto, durante a década de 1990 os países da América Latina, como o Brasil, passaram por reformas de Estado para se adequar às metas do projeto neoliberal, buscando atingir a almejada estabilidade econômica e o equilíbrio fiscal, de acordo com as exigências dos organismos multilaterais de financiamento, tais como o Banco Mundial $\mathrm{BM}$ ) - e o Fundo Monetário Internacional - FMI.

No decorrer da década de 1980 o Brasil estava num processo de reorganização social e política, depois de ter vivenciado vinte e um anos de uma ditadura civil-militar. $\mathrm{O}$ país experimentou o retorno de algumas experiências no âmbito democrático, como o reflorescimento dos movimentos sociais e de parcelas da sociedade civil organizada, ocupando as ruas, exigindo eleições diretas e ampliação dos direitos sociais. A Constituição de 1988 foi o resultado desse levante onde a seguridade social, saúde, moradia, educação, que entre outros foram assegurados pela lei, e que também teve como desdobramento a promulgação do Estatuto da Criança e do Adolescente em 1990.

Entretanto, em função do caráter dependente e periférico da economia, os ecos da crise do capitalismo e o discurso da ineficiência do Estado surgiram a partir de meados da década de 1980. Nesse momento, o país passava por um processo inflacionário acentuado, somado à grave crise econômica. A partir disso, as organizações multilaterais de financiamento, dos quais se destacam o FMI, propunham para os países "em desenvolvimento" atingirem a tão almejada estabilidade econômica, a reforma do Estado a fim de atrair os investidores estrangeiros e inserir o país no mundo globalizado.

Nesse contexto, durante a gestão de Fernando Henrique Cardoso foi proposta a reforma do Estado brasileiro, mediante a criação do Ministério da Administração e Reforma do Estado - Mare -, em 1995. Segundo o discurso oficial, a ação do Estado teria sido excessiva, sobretudo, com a ampliação de direitos sociais assegurados pela Constituição de 1988. Portanto, o objetivo da reforma do Estado seria aprimorar sua capacidade de governabilidade, além de flexibilizar e tornar mais eficiente a administração pública. De acordo com o documento norteador do Mare, o modelo vigente de administração pública era excessivamente burocrático e, portanto, considerado ineficiente. A partir disso foi proposto o modelo gerencial que, de acordo com o mesmo documento já citado, seria voltada para o atendimento da cidadania e buscaria maior qualidade nos serviços oferecidos (Peroni, 2003).

Nesse quadro, ocorreu uma acentuada retração de investimentos no âmbito das políticas sociais, pois o modelo gerencial de administração busca a redução de custos, além da autonomia do administrador no gerenciamento dos recursos, com foco nos resultados. Estas alterações eram consideradas essenciais para se adequar às novas necessidades do capital, já que direitos e conquistas eram vistos como empecilhos para acumulação capitalista.

É importante destacar, ainda, que, em função das transformações no processo produtivo e a inserção do Brasil no processo de mundialização do capital, acarretou em que o patamar de escolarização tivesse que ser alterado. Para a realização de trabalhos simples, o ensino fundamental passou a ser a exigência mínima. Entretanto, no caso dos trabalhos complexos, que até então era exigido para sua realização o ensino técnico e o ensino superior, a partir da década de 1980 foi alterado exclusivamente para o nível superior de ensino (Neves, 2000) 
Portanto, nesse contexto de redefinição do papel do Estado brasileiro, as políticas educacionais passaram por uma reformulação para se adequar às necessidades do mercado, principalmente a educação superior, que se tornou um produto lucrativo para o setor privado. Para Lima (2007) essa mudança, principalmente no ensino superior se justificou pela necessidade de adequação dos países periféricos "a nova ordem mundial globalizada e a sociedade da informação" (p. 21).

Além disso, neste cenário de flexibilidade, agilidade, liquidez das relações produtivas e de acumulação de capital exigiu-se uma nova concepção de formação de intelectuais e, portanto, o sistema educacional seria o responsável por propiciar a formação desse novo tipo de profissional, contribuindo para o crescimento econômico do país e do capital estrangeiro (Neves, 2002).

A partir disso, no decorrer da década de 1990, o Estado brasileiro vem, gradativamente, promovendo uma série de reformas no ensino superior, com o objetivo de elevar os níveis de produtividade e de competitividade, amparados na lógica empresarial, fundamentada na racionalidade econômica. Para Neves (2002), a reorganização do ensino superior ocorreu em função da imposição de um novo patamar de qualificação para os trabalhadores, simultaneamente à implantação das políticas neoliberais.

Neste contexto, nas reformas neoliberais elaboradas para o sistema educacional, tanto para os países centrais, quanto para os países periféricos, a educação foi determinante para o processo de reestruturação produtiva, pois auxiliou o processo de divisão social do trabalho. Portanto, o sistema educacional seria responsável pela formação do trabalhador que desempenharia o trabalho simples e o trabalho complexo. Ou seja, na divisão social do trabalho, diferenciaria quem pensa - os intelectuais - e quem executam - os trabalhadores em geral, como da construção civil, comércio, etc. -, trabalho manual versus trabalho intelectual (Lima, 2007).

Com isso, houve a exigência dos setores tanto da burguesia, quanto da classe trabalhadora para que o Estado reorganizasse o sistema educacional arcaico, perante os avanços tecnológicos que se modernizavam e fomentavam a estrutura econômica, exigindo mais qualificação dos trabalhadores para se inserirem no mercado de trabalho. Portanto, nas últimas décadas, a educação superior vem passando por mudanças, que se processou em nível mundial, o que culminou a "necessidade de expansão do sistema, o que vem ocorrendo, mesmo com diferenças variáveis entre os países" (Mancebo et al, 2015, p. 33).

Para Mancebo et al (2015), o processo de expansão do ensino superior no Brasil foi executado a partir de quatro eixos principais: o aumento expressivo de matrículas no setor privado de instituições de ensino superior, principalmente, com o Programa Universidade para Todos - Prouni; a expansão I, em 2003, com o objetivo de interiorização das universidades públicas e o Programa de Apoio a Planos de Reestruturação e Expansão das Universidades Federais - Reuni; a intensificação do ensino a distância e a criação da Universidade Aberta do Brasil; e a ampliação da pós-graduação com fins lucrativos do conhecimento.

O chamado processo de empresariamento da educação superior (Neves, 2002) no Brasil, ou seja, a expansão do ensino superior no setor privado cresceu acentuadamente, em relação ao setor público, como demonstrou Mancebo et al (2016) no crescimento das

\begin{tabular}{|l|l|l|l|l|r|} 
Regae: Rev. Gest. Aval. Educ. & Santa Maria & v. 7 & n. 16 & Set./dez., 2018 & p. 91-100
\end{tabular} 
matrículas presenciais e a distância, tendo como referência o período de 1995 a 2014. De acordo com os autores, saímos do patamar de 1.759 .703 matrículas, em 1995 para 7.828.013 matrículas, no ano de 2014 (p. 211)

Em conformidade com a expansão do ensino superior privado que ocorreu no período exposto acima, no ano de 2016, obtivemos um número total de 2.407 instituições de ensino superior. Segundo sua esfera administrativa, as IES estavam assim distribuídas: 2.111 IES privadas e 296 IES públicas, ou seja, 87,7\% da educação superior são monopolizadas pelo setor mercadológico e, apenas 12,3\% são IES públicas (MEC, 2016).

Neste contexto, o foco do artigo será a análise do programa Reuni, como uma das políticas educacionais de expansão da educação superior no Brasil para as universidades federais. O objetivo do artigo é o de problematizar a implementação dessa política em um dos campi da Universidade Federal Fluminense, situado na cidade de Campos dos Goytacazes: o Instituto de Ciências da Sociedade e Desenvolvimento Regional - ESR.

Posteriormente, mediante um levantamento bibliográfico baseado em alguns autores como Evangelista et al (2011), Lima (2007), Mancebo et al (2015), Mancebo et al (2016), Saviani (2010), Neves (2002) pretende-se abordar a gênese do programa Reuni como um dos sustentáculos das políticas de governo para a expansão da educação superior no país. Em seguida, por meio de análise documental ${ }^{1}$, ir-se-á relatar a experiência de implementação da expansão no ESR por meio do Reuni.

\section{Políticas educacionais para o ensino superior público: direito ou mercadoria?}

A crise estrutural sofrida pelo capitalismo durante a década de 1970 abalou as estruturas do regime de acumulação fordista-keynesiano (Harvey, 2008) e exigiu uma reestruturação de seu sistema produtivo. Em resposta à crise, o capital financeiro se articulou aos capitais nacionais, para que o capitalismo recuperasse o fôlego, por meio do projeto neoliberal, cujo objetivo central foi o de reconstituição do mercado livre e a redução e/ou eliminação da intervenção do Estado na garantia dos direitos sociais universais (Montãno, 2014).

Essa crise refletiu-se na América Latina a partir dos anos 1980 e 1990 e, as frações das classes dominantes presentes no Estado brasileiro viram nas recomendações do Consenso de Washington a principal estratégia de enfrentamento dessa crise que, ocorreu basicamente, segundo Bresser-Pereira (1991) pelo protecionismo do Estado e a indisciplina fiscal. O Consenso de Washington propôs dez reformas para ser implementado por meio de políticas econômicas nos países da América Latina. No entanto, as cinco primeiras tiveram por objetivo "promover a estatização da economia através do ajuste fiscal e o mercado como prioridade central destas políticas. As demais sugeriram que a função do Estado deveria ser reduzida" (Bresser-Pereira, 1991, p. 6).

\footnotetext{
${ }^{1}$ Análise documental refere-se aos documentos referentes ao ESR no que diz respeito ao Reuni, como atas do colegiado de unidade, memorandos, projeto de expansão do Polo de Campos dos Goytacazes, detalhamento do projeto de expansão via Reuni.

Regae: Rev. Gest. Aval. Educ. Santa Maria v. 7 ก. 16 Set./dez., 2018 p. $91-110$
} 
De acordo com Peroni (2013) foi no governo de Fernando Collor de Mello, o primeiro presidente eleito por eleições diretas em 1989, após o fim de 21 anos de ditadura militar, pelo Partido da Renovação Nacional - PRN -, que colocou em "prática a minimização do papel do Estado para com as políticas sociais e de privatização e mercantilização do público" (p. 19).

Em 1995, no governo de Fernando Henrique Cardoso, se intensificou o projeto de reforma do Estado, com a finalidade de reorganizar a economia brasileira que passava por uma crise fiscal. Portanto, a reforma do Estado passa pela "redefinição do papel do Estado" (Peroni (2013, p. 58), que deve ser máximo para a defesa do mercado financeiro e, mínimo para garantir a execução das políticas sociais.

Para por em prática o pacote de ajuste fiscal proposto pelas organizações multilaterais de financiamento, foi criado o Ministério da Administração Federal e Reforma do Estado. Seu ministro foi Bresser Pereira, que apresentou o documento Plano Diretor da Reforma do Aparelho de Estado, sustentado nos seguintes pilares do projeto neoliberal: privatização, publicização e a terceirização (Peroni, 2003, p. 60).

Portanto, buscando atingir os objetivos expostos, a proposta de reforma do Estado brasileiro adotou três estratégias principais, com o objetivo de aprimorar o nível de qualidade dos serviços públicos: a privatização, que é a de transferir para a área privada as atividades que podem ser controladas pelo mercado; a terceirização, que seria a de repassar para o setor privado os serviços considerados de apoio e, por fim, a publicização, que é a transferência para o novo setor chamado público não-estatal, as atividades de natureza social e científica prestadas pelo Estado. Nesse caso, os serviços sociais, nos quais se inclui a educação, passariam a ser gerenciados por organizações sociais, consideradas mais "eficientes" nesse novo modelo estatal, pois são entidades de direito privado, que são, em sua maioria, subvencionadas pelo poder público. De acordo com Comerllato e Caetano (2013)

a razão da lógica privada, assim como a do mercado, de intervir nas "questões públicas" é ideologicamente justificada pelo diagnóstico da ineficiência da gestão pública, afirmando que "tudo que é público e gratuito é ineficiente". Ou seja, sob o ponto de vista do sistema capitalista, a educação pública precisa ser gerida como empresa, pois é na lógica empresarial que se encontram os critérios, processos e indicadores de gestão eficiente e de sucesso. (p. 247)

Sendo assim, nesse contexto, de redefinição do papel do Estado e das transformações no modo de produção capitalista é que as políticas voltadas para a educação superior são reformuladas, a partir da redução do Estado neste âmbito do ensino e sua aproximação com os parâmetros do mercado, buscando eficiência, produtividade e ampliação do acesso. Isto vem ocorrendo mediante a opção de frações da classe dominante, que lucram com o empresariamento do ensino, em expandir o ensino privado superior, ao mesmo tempo em que o ensino superior público é redefinido e necessita ser expandido para atender às demandas das transformações na esfera produtiva. 
No ano de 1996, o ensino superior no país possuía o total de 1.868 .529 alunos, sendo que 725.427 (39,35\%) estavam matriculados no setor público e 1.133 .102 (60,65\%) no setor privado. Em 2005, o total de alunos no ensino superior brasileiro era de 4.453.156, sendo que $1.192 .189(26,77 \%)$ estavam matriculados no setor público e 3.260 .967 no setor privado.

No processo de elaboração da nova política educacional brasileira existiram dois projetos em disputa, ideologicamente, antagônicos. O primeiro referia-se à proposta do projeto de lei da LDB que representou a construção e elaboração coletiva de movimentos e entidades que lutavam pela educação, pública, gratuita e universal, a partir do Fórum Nacional em Defesa da Escola Pública - PL n. 1.258/88 (Lima, 2007). O segundo, ao projeto de lei n. 101/93. elaborado pelo senador Darcy Ribeiro, que, naquele momento, representava a proposta do governo federal, e mais tarde foi quase completamente incorporado ao texto final Lei de Diretrizes e Bases da Educação Nacional - lei n. 9.394, de 20 de dezembro de 1996 -, "que dá mais um passo no sentido da sedimentação do processo de empresariamento da educação superior" (Neves, 2002, p. 139).

As categorias chaves na redação da LDB n. 9.394/1996 centrou-se na gestão democrática do ensino público; autonomia pedagógica, administrativa e financeira; avaliação e formação de professores. Porém, houve uma distorção dessas categorias, para atender as diretrizes do projeto neoliberal, que se preocupou, naquele momento, reduzir o número de analfabetismo no país, pois necessitava de mão de obra profissionalizante para as demandas do processo produtivo. Sendo assim, Evangelista et al (2011, p. 44) apontou que a

capacitação de professores foi traduzida como profissionalização; participação da sociedade civil como articulação com empresários e ONGs; descentralização como desconcentração da responsabilidade do Estado; autonomia como liberdade de captação de recursos; igualdade com equidade; cidadania crítica como cidadania produtiva; formação do cidadão como atendimento ao cliente; melhoria da qualidade como adequação ao mercado, e, finalmente, o aluno foi transformado em consumidor.

A LDB n. 9.394/96 instituiu, no artigo 87, inciso 10, a Década da educação e estabeleceu o prazo de um ano para envio ao Congresso Nacional do Plano Nacional de Educação, com diretrizes e metas para os dez anos seguintes, conforme a Declaração Mundial sobre Educação para Todos.

Em função disso, após a Constituição Federal (1988) e a LDB n. 9.394/1996, iniciaram-se as discussões no âmbito do Estado e da sociedade civil referente à elaboração do PNE implementado por meio da lei n. 10.172, de 9 de janeiro de 2001, durante o governo FHC (Brasil, 2001). Entretanto, em função da existência de projetos antagônicos de sociedade e de educação, geraram-se tensões no campo educacional, que foram materializadas mediante a proposta do governo e o projeto encabeçado pelo campo democrático de massas sobre o PNE (Neves, 2008). Entre as divergências, destaca-se que o projeto democrático de massas convocou a participação da sociedade civil, mediante os participantes do II Congresso Nacional de Educação, com o objetivo de definir, coletivamente, sobre as metas da educação escolar para os próximos anos (Neves, 2008). Na proposta governamental, a participação da sociedade civil foi
Regae: Rev. Gest. Aval. Educ.
Santa Maria
v. 7
n. 16
Set./dez., 2018
p. $91-110$ 
estritamente em caráter consultivo. Destaca-se, ainda, o vínculo do PNE do governo com o setor empresarial, ressaltando a articulação das instâncias do Estado com a proposta neoliberal de sociedade.

De acordo com Dourado (2011), o PNE caracterizou-se como um plano formal, sobretudo pela inexistência de mecanismos efetivos de financiamento e de regulamentação no que se refere ao regime de colaboração entre as diferentes instâncias da federação. Além disso, segundo o mesmo autor, o plano enfatizou o estreitamento das fronteiras entre as esferas pública e privada, principalmente em relação à educação superior, com o surgimento de novos mecanismos de privatização (Dourado, 2011).

Por isso, quando se tratou dos objetivos e metas do PNE, já em seu artigo $1^{\circ}$ e $3^{\circ}$ este orientou para que "até o final da década, o acesso ao ensino superior deveria atingir até $30 \%$ da faixa etária de 18 a 24 anos", bem como elaborar uma "política de expansão com a finalidade de diminuir as desigualdades de oferta existentes entre as regiões do país". Os recursos para que fossem cumpridas essas metas dependeria do orçamento da União. Assim, a LDB e o PNE corroboraram para a legitimação da privatização da educação superior no Brasil, por meio da "diversificação das IES e dos cursos e a diversificação de suas fontes de financiamento" (Lima, 2007, p. 135).

Umas das diretrizes para a educação superior reforçou a mudança que houve no processo de reorganização da acumulação flexível de produção e, com isso, o novo perfil de trabalhador necessário para atuar no mercado mais flexível, momentâneo e específico:

As IES têm muito a fazer, no conjunto dos esforços nacionais, para colocar - País à altura das exigências e desafios do Séc. XXI, encontrando a solução para os problemas atuais, em todos os campos da vida e da atividade humana e abrindo um horizonte para um futuro melhor para a sociedade brasileira, reduzindo as desigualdades. A oferta de educação básica de qualidade para todos está grandemente nas mãos dessas instituições, na medida que a elas compete primordialmente a formação dos profissionais do magistério; a formação dos quadros profissionais, científicos e culturais de nível superior, a produção de pesquisa e inovação, a busca de solução para os problemas atuais são funções que destacam a universidade no objetivo de projetar a sociedade brasileira num futuro melhor (PNE, 2001, p. 33)

Ao mesmo tempo em que os intelectuais do neoliberalismo defenderam (e defendem) o discurso da educação como propulsora do desenvolvimento econômico do país e elemento que reduz a desigualdade social, o governo FHC reduziu, consideravelmente, os recursos para as universidades federais durante seus dois mandatos. Os servidores públicos do Executivo não receberam reajuste salarial durante toda a sua gestão e os concursos públicos para docentes, técnicos e administrativos para repor os recursos humanos não foi realizado, sendo retomados somente no governo posterior com a política de expansão da rede federal de educação superior.

Alguns dados comprovam o "esfacelamento geral" (Mattei, 2014) das instituições federais de ensino superior, relacionado aos recursos financeiros do Fundo Público Federal que, gradativamente, foi reduzindo, ao longo da gestão do FHC (1995-2002). Em 
relação ao pagamento de pessoal ${ }^{2}$ foram reduzidos de $R \$ 14$ bilhões, em 1994 para $R \$$ 12,9 bilhões; em relação aos recursos para garantir a efetiva manutenção das Ifes ${ }^{3}$ foram reduzidos de $R \$ 1.660$ milhões, em 1994 para $R \$ 633$ milhões no ano de 2002; e, no que se refere aos recursos para investimentos em obras, equipamentos, livros, etc., de $R \$ 362$ milhões, em 1994 para $\mathrm{R} \$ 49$ milhões, em 2002 (Amaral, 2009).

Nesse mesmo contexto, o Fundo de Financiamento do Estudante de Ensino Superior - Fies -foi criado no governo de FHC, no ano de 1999, substituindo o Crédito Educativo. Este esteve vigente durante 24 anos (1975 a 1999), "concedendo empréstimo para o pagamento de mensalidades e manutenção de estudantes supostamente carentes matriculados em IES privadas" (Davies, 2000, p. 172). Portanto, o Creduc beneficiou o setor privado e onerou os cofres públicos, pois era financiado com recursos públicos, sobretudo, pelo alto índice de inadimplência que chegou a " $\mathrm{R} \$ 2,46$ bilhões, num total de 145.353 mil contratos ativos no ano de 2005" (Queiroz, 2015, p. 46).

Com isso, depois da MP n. 1.827, de 27 de maio de 1999 ter sido reeditada 25 vezes, foi promulgada a lei n. 10.260, em 12 de julho de 2001, que legitimou o Fies. Nesse contexto, o setor privado educacional continuou expandindo suas fronteiras, durante o governo de Luís Inácio Lula da Silva (2003-2010), com percentual de 74,2\% de matrículas nas IES privadas, no ano de 2010 (Mancebo et al, 2015). No período entre 1995 a 2014, conforme a mesma autora apontou (2016, p. 211) houve uma grande "expansão das matrículas nas instituições privadas, um crescimento de $454 \%$, enquanto que na rede pública o aumento foi de somente $180 \%$ ".

O governo do Partido dos Trabalhadores promoveu o discurso de expandir o acesso ao ensino superior às classes historicamente excluídas dessa modalidade de ensino, ao mesmo tempo em que ampliou o número de concessões ao empresariado do setor educacional. Com esse propósito, criou o Programa Universidade para Todos - Prouni -, que foi lançado oficialmente em 13 de maio de 2004, pelo ex-presidente Luís Inácio Lula da Silva e foi institucionalizado pela lei n. 11.096, em 13 de janeiro de 2005. Este tinha por finalidade "a concessão de bolsas de estudo integrais e parciais em cursos de graduação e sequenciais de formação específica, em instituições privadas de educação superior. Em contrapartida, oferecia isenção de impostos às instituições de ensino que aderem ao programa" (Brasil, 2005).

A origem do Prouni partiu de dois argumentos centrais do MEC: o primeiro, a partir das pesquisas coordenadas pelo Instituto Brasileiro de Geografia e Estatística e do Censo da Educação Superior foi constatado que entre os jovens na faixa de 18 a 24 anos, somente $9 \%$ frequentavam o ensino superior. Esse número comprovou o caráter elitista da educação superior no país, segundo o governo federal. O segundo fundamentou-se no alto índice de vagas ociosas nas instituições privadas de ensino superior. Essas seriam preenchidas "por meio da concessão de bolsas de estudos para estudantes considerados pobres (com renda familiar per capita de até um salário mínimo) e que cursaram o ensino médio em escolas públicas, aos professores da rede pública do ensino fundamental sem diploma de nível superior, aos negros, pardos e indígenas" (Lima, 2007, p. 172).

2 De acordo com Amaral (2009), o pagamento de pessoal se refere ao corpo docente, o corpo técnico e administrativo, bem como, aposentados, pensionistas e precatórios.

3 Esses recursos correspondem ao pagamento de salários indiretos como, por exemplo, o vale-transporte, auxílio-alimentação, assistência médica, auxílio-creche (Amaral, 2009).
Regae: Rev. Gest. Aval. Educ.
Santa Maria
v. 7
n. 16
Set./dez., 2018
p. $91-110$ 
De acordo com a mesma autora acima citada, a pressão privatista do empresariado sobre o conceito de pobreza alterou os critérios de concessão de bolsa, passando a vigorar a bolsa integral de $100 \%$ para estudantes pobres que comprovarem a renda per capita da família de até um salário mínimo e meio e para os estudantes que apresentarem a renda per capita da família de até três salários mínimos receberão a bolsa parcial de $50 \%$. Além disso, os beneficiários das bolsas do Prouni deverão prestar serviços comunitários, conforme a lei n. 9.608, de 18 de fevereiro de 1998, que instituiu o trabalho voluntário. Em relação às instituições privadas que aderiram ao Prouni, estas "deverão oferecer uma bolsa integral de $100 \%$ para cada nove alunos pagantes matriculados num de seus cursos de graduação" (p. 173). O acesso dos estudantes às instituições de ensino superior privadas por meio do Prouni seria realizado por meio do Exame Nacional do Ensino Médio - Enem.

Nesse contexto, o governo federal, em 24 de abril de 2007, efetivou o decreto $n$. 6.094 que regulamentou o Plano de Desenvolvimento da Educação, em conjunto com o Plano de Metas Compromisso Todos pela Educação que foi carro-chefe do PDE, com o objetivo de melhorar a qualidade da educação no país. Isso, inclusive, mostrou a articulação do governo federal com o movimento Todos pela Educação, formado por "um aglomerado de grupos empresariais com representantes e patrocínio de entidades como - Grupo Pão de Açúcar, Fundação Itaú-Social, Fundação Bradesco, Instituto Gerdau, Grupo Gerdau, Fundação Roberto Marinho" (Saviani, 2009, p. 32).

O governo criou o PDE paralelamente ao PNE, passando longe do disposto no PNE (Saviani, 2009). O PDE focalizou suas metas na educação básica, pois "preocupado com o problema da qualidade da educação básica, lançou três programas no seu enredo: o Índice de Desenvolvimento da Educação Básica, o Provinha Brasil e o Piso do Magistério. Trata-se de uma proposta do executivo federal para solucionar o problema da qualidade do ensino público no país. Portanto, o MEC queria discutir o problema da qualidade do ensino avaliando a educação básica, ou seja, atribuindo quanta vale o ensino de cada escola, quantificando, por meio de ranking nacional $e$, induzindo à competição, ao invés de investir recursos públicos nas escolas públicas. A solução do problema da qualidade de ensino na educação básica encontra-se, sobretudo, na ampliação das fontes de financiamento público na educação básica e na educação superior, bem como na existência de um plano de carreira para os professores da educação básica e na valorização profissional.

Para Saviani (2009, p. 45) o PDE teve características da lógica do mercado, orientado pela "pedagogia das competências" e da "qualidade total", pois esta, "assim como nas empresas, visa obter a satisfação total dos clientes e interpreta que, nas escolas, aqueles que ensinam são prestadores de serviço e os que aprendem são clientes; e a educação é um produto que pode ser produzido com qualidade variável". A "qualidade variável" depende da avaliação, do financiamento, da satisfação dos clientes e dos "ajustes às exigências postas pela demanda das empresas" (Saviani, 2009).

No que se refere à educação superior, o PDE elaborou onze ações: i) Fundo de Financiamento Estudantil ${ }^{4}$ e Prouni; ii) Pós-doutorado; iii) Professor-equivalente; iv) Educação superior, cuja meta é duplicar, em dez anos, o número de vagas nas

${ }^{4}$ Criado pela lei n. 10.260, de 12 de julho de 2001.

Regae: Rev. Gest. Aval. Educ. Santa Maria v. 7 n. 16 Set./dez., 2018 p. $91-100$ 
universidades federais; v) Programa Incluir: acessibilidade na educação superior; vi) Programa de Apoio à Extensão Universitária; vii) Prodocência; viii) Nova Coordenação de Aperfeiçoamento de Pessoal de Nível Superior; ix) Iniciação à Docência - cria o Programa de Bolsa Institucional de Iniciação à Docência; $x$ ) Incentivo à Ciência - aproximação das universidades das empresas mediante a redução fiscal a empresas que investir em projetos de inovação científica e tecnológica; e xi) Formação da Saúde ( Saviani, 2009, p. 10-11).

Essas ações previstas no PDE se desdobraram em cinco princípios que se complementam entre si: i) expansão da oferta de vagas; ii) garantia da qualidade; iii) promoção da inclusão social pela educação; iv) ordenação territorial para tornar o ensino acessível; e v) desenvolvimento econômico e social (lbidem, p. 18).

Para efetivar esse conjunto de metas, O PDE previu três principais políticas educacionais: i) Programa de Apoio a Planos de Reestruturação e Expansão das Universidades Federais e o Plano Nacional de Assistência Estudantil ${ }^{5}$; ii) Democratização do acesso nas instituições particulares; e iii) Avaliação como base da regulação: Sistema Nacional de Avaliação da Educação Superior ${ }^{6}$ (Ibidem, p. 19).

O Programa Reuni, que é o foco do artigo, foi criado por meio do decreto presidencial n. 6.096, de 24 de abril de 2007, sendo uma política de governo elaborada para a expansão da educação superior no âmbito federal. No artigo $1^{\circ}$ definiu que seu objetivo seria a ampliação do acesso e da permanência no ensino superior, em cursos de graduação presenciais, aproveitando a estrutura física e os recursos humanos existentes nas universidades federais. Foi elaborado somente para as universidades federais e

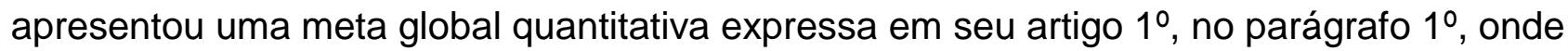
mencionou a elevação do índice da taxa de conclusão dos cursos de graduação presenciais para $90 \%$ e do número de alunos por professor, na média de 18 alunos, para cada docente.

A política educacional para as universidades federais foi elaborada a partir de seis diretrizes que modificaram a gestão política, administrativa e acadêmica dessas instituições. Para gestão acadêmica se propôs uma reestruturação acadêmico-curricular, que previu uma reformulação dos cursos de graduação e a diversificação de suas modalidades, com a finalidade de evitar a "profissionalização precoce e especializada" (PDE, 2007, 11). Com isso, os Bacharelados Interdisciplinares (B.I.) são vistos como alternativas pedagógicas para reorganização curricular. A primeira experiência de aplicação foi a Universidade Federal da Bahia, na gestão do ex-reitor Naomar de Almeida Filho, que foi o idealizador do projeto Universidade Nova, que tinha como centro de discussão os B.I., composto pelo regime de três ciclos.

O Projeto Universidade Nova se fundamentou nos paradigmas de universidades estadunidenses, e, principalmente, o europeu. A Declaração de Bolonha teve como finalidade a padronização do ensino superior por meio da reestruturação curricular que

${ }^{5}$ Instituído pelo decreto n. 7.234, de 19 de julho de 2010.

${ }^{6}$ Criado pelo lei n. 10.861, de 14 de abril de 2004.

Regae: Rev. Gest. Aval. Educ. Santa Maria v. 7 ก. 16 Set./dez., 2018 p. $91-110$ 
propiciasse um currículo mais maleável, formando "bacharéis genéricos e flexíveis" (Paula, 2009, p. 172). Portanto, o programa Reuni tem sua gênese no Plano Universidade Nova, "convergindo em torno de um modelo flexível de educação superior ou formação humana" (Paula, 2009, p. 205).

As universidades federais que assinaram o termo de adesão do programa Reuni teriam cinco anos para atingir essa meta, a contar da data da assinatura do contrato. Portanto, para combater os índices de evasão e, principalmente, a inadimplência nas IES privadas o governo federal utilizou o Prouni e o Fies, e às universidades federais, que também tinham o problema da evasão nos cursos, de vagas ociosas, e de docentes ministrando disciplinas, muitas vezes, para um número reduzido de estudantes, o Reuni vem no sentido de gerenciar, regular e exigir dos gestores e dos docentes, a eficiência e a produtividade, por meio da melhora dos índices.

O primeiro índice a ser melhorado foi indicado no artigo $2^{\circ}$ do decreto, sobre "a redução das taxas de evasão, ocupação de vagas ociosas e aumento de vagas de ingresso, especialmente, para o período noturno". Na concepção do Governo Federal, essa diretriz do Reuni é o centro do problema a ser combatido nas universidades federais: o mau aproveitamento dos recursos humanos. O ensino passou a ser prioridade, e a indissociabilidade entre ensino, pesquisa e extensão é prejudicada, pois se o docente fica mais tempo em sala de aula, esta ocupada com 60 a 70 estudantes na disciplina ministrada por ele, o professor teria seu tempo reduzido para as atividades de pesquisa $e$ extensão. De acordo com Lima (2012), "a lógica imposta pelo Reuni - sua centralidade no ensino da graduação - constitui uma das faces da intensificação do trabalho docente na atualidade, da certificação em larga escala e da quebra da indissociabilidade entre ensino, pesquisa e extensão" (p. 445).

Para que o programa Reuni fosse implementado no ano de 2008, ocorreu uma primeira chamada no dia 29 de outubro de 2007, no qual das 54 universidades existentes neste ano, 42 universidades assinaram o termo de adesão à implementação da política. Neste momento, a Universidade Federal Fluminense foi a última a aderir ao programa ${ }^{7}$, fruto das mobilizações contrárias da comunidade universitária que previam o avanço da precarização das universidades federais. As demais universidades firmaram acordo com o Ministério da Educação no dia 17 de dezembro de 2007.

É importante ressaltar que, além das universidades formularem seu plano de reestruturação seguindo as orientações do MEC, por meio das dimensões e de seus aspectos específicos, deveria haver um aumento mínimo de $20 \%$ nas matrículas dos cursos de graduação. Em contrapartida, as universidades federais, diante dos congelamentos orçamentários que vêm ocorrendo nas instituições de ensino superior públicas desde a década de 1990, criam expectativas no repasse que o MEC realizaria de recursos financeiros de $20 \%$ das despesas de custeio e pessoal da universidade, no período de cinco anos, prazo limite de término de aplicação das metas da política (artigo

\footnotetext{
7 Este estudo foi realizado por Predes (2015), sendo o "Apêndice G: as universidades federais e a expansão no governo Lula.

Regae: Rev. Gest. Aval. Educ. 
$3^{\circ}$, parágrafo $1^{\circ}$ ). Porém, esses recursos estão condicionados à conta das dotações orçamentárias do MEC. Portanto, enquanto o MEC tiver recursos financeiros, o Reuni se mantém. O contrário, diante de um cenário econômico recessivo, o ministério e, consequentemente, o REUNI, receberia menos recursos.

Portanto, 53 universidades federais, no ano de 2007 assinaram o contrato de gestão do Reuni e se submeteram a cumprir as regras impostas pelo MEC, "em certificar em massa, mas à custa da flexibilização e rebaixamento dos cursos e da intensificação do trabalho docente" (Mancebo et al, 2015, p. 47).

De acordo com Lima (2012), nesse novo contexto, "o docente é configurado enquanto trabalhador de um sistema produtivo-industrial, imerso numa nova organização do trabalho" (p. 101). Se a concepção do trabalho docente se modificou, é porque a concepção de universidade pública, também sofreu mudanças na sua gestão administrativa, acadêmica e política. A universidade, mais parecida com uma indústria, precisa produzir seu produto sob medida aos moldes do mercado flexível, volátil e competitivo. Portanto, se a concepção de universidade, de trabalho docente se transformou para atender às demandas do mercado, o produto final, que é a formação acadêmica do estudante, também sofreu consequências.

A UFF teve a evolução de crescimento do número de vagas oferecidas entre os anos de 2006 a $2014 \mathrm{em} 222 \%{ }^{8}$. O número de alunos matriculados duplicou nestes anos: de 25.344 para 52.936 matrículas $^{9}$. Porém, neste relatório, não consta uma avaliação mais aprofundada sobre a elevação da taxa média de conclusão dos cursos de graduação presenciais e se a taxa de evasão diminuiu. Por mais que o Reuni tenha finalizado seu prazo de aplicabilidade, os estudos sobre a avaliação desta política ainda são recentes e polêmicos.

Alguns autores como Lima (2007), Mancebo (2016), Neves (2002), Saviani (2010) defendem que o programa Reuni reproduz a lógica do mercado, no momento que segue os ditames dos instituições internacionais para a implementação de políticas de ensino superior dos países periféricos. Sendo assim, para esses pesquisadores, o Reuni resultou num processo de massificação da entrada de jovens nas universidades federais para corresponder aos interesses do mercado de trabalho e não como um processo de democratização do acesso dos filhos da classe trabalhadora ao ensino superior público.

Por outro lado, existe o discurso de segmentos da União Nacional dos Estudantes que defenderam a entrada dos jovens nas universidades, a partir de 2008, como positiva e se intitulam reunistas. Justificam que pelo Reuni e pelas políticas de ações afirmativas tiveram acesso ao ensino superior e, com isso, houve a democratização do acesso a setores da classe trabalhadora que sempre foram excluídos dos bancos das universidades, principalmente os pobres e negros.

\section{O Reuni no ESR: campi da UFF em Campos dos Goytacazes}

A Universidade Federal Fluminense - UFF - foi criada pela lei n. 3.848, de 18 de dezembro de 1960, com o nome de Universidade Federal do Estado do Rio de Janeiro, com sede na cidade de Niterói, e se constituiu pela incorporação de cinco faculdades

8 Conforme Relatório de estão 2006-2014 da UFF.

9 Conforme Relatório de gestão 2006-2014 da UFF.

Regae: Rev. Gest. Aval. Educ. Santa Maria 
federais já existentes, três escolas estaduais e duas particulares. Após dois anos de sua existência, a UFF já estava inserida na cidade de Campos dos Goytacazes, pois, no mesmo ano de 1962, foi criado o Departamento de Serviço Social de Campos. É importante ressaltar que essa extensão da UFF em Campos representava a única instituição pública de ensino superior da região. As instituições privadas lideravam o ensino superior da cidade e dos entornos. De acordo com Borowsky e Silva (2016) ${ }^{10}$ :

Para atender a demanda das mudanças socioeconômicas e culturais e suprir a carência de universidades públicas no norte e noroeste fluminense, o SSC propõe à UFF ampliar sua condição de departamento e se tornar instituto. O Instituto de Ciências da Sociedade e Desenvolvimento Regional (ESR) foi aprovado pelo Conselho Universitário da UFF em 1999, sendo constituído de dois departamentos: Departamento de Serviço Social (SSC) e o Departamento de Fundamentos de Ciências da Sociedade (SFC). O ESR oferecia o curso de graduação em Serviço Social, com extensão de turma no município de Bom Jesus do Itabapoana, no Noroeste Fluminense totalizando 587 alunos de graduação, além de três cursos de pós-graduação lato sensu. (p. 6)

Em 1993 foi criado um projeto de extensão para atender o público da terceira idade denominado: Universidade para Terceira Idade. Em agosto deste ano a Uniti completará 25 anos e de projeto se tornou um programa de extensão do ESR, devido a sua importância no trabalho que realiza junto à comunidade campista.

Em agosto 2005 iniciaram-se os seguintes cursos de pós-graduação: a Especialização em Serviço Social Contemporâneo: Questão Social, Planejamento e Gestão de Políticas Públicas; Meio Ambiente e Desenvolvimento Regional, em março de 2006 e o de Gerontologia Social e Políticas Públicas em abril de 2006. Os três cursos lato sensu eram auto-financiáveis e a maioria do quadro docente pertencia ao ESR. Nos dias 20 e 21 de junho de 2006 ocorreu o I Seminário da Pós-Graduação do ESR, com aproximadamente 330 candidatos para participar deste evento.

Um fato importante a ser mencionado foi que, no ano de 2005, o ESR elaborou o projeto Implantação e consolidação do pólo universitário de Campos dos Goytacazes e enviou ao MEC a solicitação do processo de interiorização. Uma das justificativas da interiorização, além de formar uma rede de ensino superior público em Campos, com a Universidade Estadual do Norte Fluminense Darcy Ribeiro, que desde 16 de agosto de 1993 atua na formação de novos profissionais na cidade, assim como o Centro Federal de Educação Tecnológica, se evidenciou no discurso do gestor do projeto de expansão de Campos dos Goytacazes em 2008. Sua preocupação era a de dar opção de escolha para os estudantes na oferta de vagas para o ensino superior e reduzir o monopólio das vagas nas instituições privadas:

\footnotetext{
${ }^{10}$ Artigo apresentado no Fórum da Gestão do Ensino Superior nos Países e Regiões de Língua Portuguesa, 6a Conferência Forges, realizado em Campinas, 2016, intitulado Filhos do Reuni: avanços e limites do programa de apoio a planos de reestruturação e expansão das universidades federais na formação acadêmica dos estudantes. Trata-se de uma pesquisa em fase de realização no mestrado de Políticas Sociais da Uenf, sob a orientação da professora Renata Maldonado da Silva. http://www.aforges.org/wpcontent/uploads/2016/11/5-Micheli-Borowsky Filhos-da-Reuni.pdf.
} 
A constatação da impressionante demanda reprimida por vagas no Ensino Superior público e gratuito, nessa grande região. Hoje, dos cerca de 28.000 estudantes de ensino superior frequentando as unidades públicas e privadas existentes em Campos, mais de 10.000 o fazem com bolsas das prefeituras, em grande parte com recursos dos royalties do petróleo e dos programas do Governo Federal. Sabemos dos problemas com a qualidade da formação nessas unidades. Ao mesmo tempo, esses números demonstram que a população brasileira tem direito, mas não tem meios de frequentar a universidade com seus próprios recursos. Por isso, o ensino superior público e gratuito, e, acima de tudo, o ensino de qualidade, constituem, além de direitos, necessidades urgentes da população. Não queremos entrar na polêmica entre ensino público e privado; acredito que uma sociedade deve assegurar aos seus cidadãos o direito de escolha entre os dois. No entanto, no quadro dos ainda baixos patamares de renda da grande maioria da população, o cidadão hoje, ainda não tem o direito de escolha; é-lhe negado o amplo acesso ao ensino superior público e gratuito; ele ingressa no ensino privado, não por escolha, mas exatamente por falta de opção ${ }^{11}$.

No entanto, circunstâncias políticas fizeram com que o projeto do pólo da UFF de Rio das Ostras, elaborado posteriormente ao do ESR, fosse contemplado em detrimento do projeto de Campos.

Contundo, os dirigentes do ESR não desanimaram com a negativa do MEC e, em 2007, com a implementação do PDE que previa a democratização do acesso ao ensino superior para as universidades federais, por meio do Reuni, consideraram uma oportunidade ímpar de garantir o crescimento do ESR e levaram o tema para discussão no Colegiado de Unidade.

Conforme a ata do Colegiado de Unidade datada de 10 de outubro de 2007 a pauta foi sobre a adesão do ESR ao programa Reuni. Uma das conselheiras solicitou que se fizesse uma apresentação do Reuni. Após a exposição, alguns conselheiros levantaram preocupações como a questão da autonomia universitária, a precarização do trabalho docente, o aumento do número de alunos por turma e a qualidade de ensino.

Outros membros defendiam que só por meio do Reuni que o ESR poderia expandir e contribuir para o desenvolvimento regional. $O$ debate foi acirrado e o programa foi aprovado, com o voto de minerva do presidente do Colegiado de Unidade: 6 votos a favor e 5 votos contra.

A partir de então, foi criada uma equipe no ESR e a disputa aconteceu na sede da UFF em Niterói, com a Comissão Mista do Conselho Universitário ${ }^{12}$. A adesão do Reuni na UFF não foi um processo tranquilo, assim como no cenário nacional, pois as universidades foram palco de disputas, confrontos e debates. A comunidade universitária

11 Esse discurso foi redigido pelo gestor que implementou o Reuni no ESR.

12 A comissão mista foi implementada pela portaria n. 37.981, de 9 de abril de 2008, e tinha por objetivo planejar, programar, implantar e acompanhar o projeto de expansão e reestruturação da UFF. A Comissão Mista era composta por membros integrantes da Comissão de Orçamento e Metas do Plano de Desenvolvimento Institucional e da Comissão de Assessoramento do CUV. http://www.uff.br/reuni/images/stories/arquivos/reuni/legislacao/portaria 37981 criao da comissao mista.pdf 
ficou dividida entre aderir ou não ao programa. Essa discussão estende-se até os dias atuais, pois em algumas universidades o número de alunos triplicou e o espaço físico não atendeu à demanda, restando apenas estruturas inacabadas. Um exemplo disso ocorreu no próprio ESR, que até a presente data, as obras do Reuni não foram concluídas.

No Projeto de Expansão e Reestruturação da UFF a proposta de distribuição de recursos para obras no período de 2009 a 2011 para o ESR de Campos dos Goytacazes era a seguinte: o total da obra era de $\mathrm{R} \$ 9.509 .883,45$ sendo a dimensão da obra de $1.140,34 \mathrm{~m}^{2}$. Esse valor seria distribuído da seguinte forma: em 2009 - $\mathrm{R} \$ 3.803 .953,58$ (40\%); em 2010 - $\mathrm{R} \$ 3.803 .953,58$ (40\%); e em 2011- $\mathrm{R} \$ 1.901 .976,69$ (20\%).

A proposta para a construção do campus novo do ESR, com as verbas do Reuni está contida na planilha do projeto. Porém, a realidade foi totalmente oposta. Esse dinheiro percorreu outros caminhos e permanecem até hoje a falta de salas de aula, gabinetes para docentes, laboratórios, enfim, o espaço físico não comporta o número de aproximadamente três mil e quatrocentos estudantes matriculados na unidade.

Assim, com a adesão da UFF ao Reuni, no segundo semestre de 2009 ingressam no ESR estudantes nas primeiras turmas dos cursos de graduação presencial em Geografia, Ciências Sociais e Ciências Econômicas.

No primeiro semestre de 2011 mais estudantes chegaram para preencher as vagas das primeiras turmas dos cursos de graduação em Psicologia e História. Os cursos de História, Geografia e Ciências Sociais ofereceram as modalidades bacharelado e licenciatura e são cursos noturnos, assim como o curso de Serviço Social. O curso de Psicologia é integral, matutino e vespertino, e o curso de Ciências Econômicas é matutino.

Além das graduações, o ESR tem três pós-graduações lato sensu em Meio Ambiente e Desenvolvimento Regional; Organização e Gestão das Instituições de Justiça Criminal e Segurança; e Serviço Social Contemporâneo e duas stricto sensu: o Mestrado em Geografia e o Mestrado em Desenvolvimento, Ambiente e Políticas Públicas.

O campi da UFF em Campos dos Goytacazes não possui restaurante universitário, moradia ou creche universitária. Mas o ESR tem uma Coordenação de Assistência Estudantil - Caes - e quatro assistentes sociais que realizam o atendimento a estudantes com dificuldades de permanência nos cursos de graduação. Em 2011 a Caes possibilitava apenas dois tipos de bolsas: a bolsa treinamento e a bolsa acolhimento. Com o aumento expressivo da entrada de estudantes no ESR, as bolsas foram ampliadas para: Programa Auxílio Alimentação para Estudantes Fora da Sede; o Programa Auxílio Creche; Programa Auxílio Moradia; Programa Auxílio Saúde; Programa Bolsa de Apoio aos Estudantes com Deficiência; Bolsa de Apoio Transporte; Programa Bolsa de Desenvolvimento Acadêmico e Programa Bolsa Alimentação.

Com a crise econômica que o país enfrenta desde o final do ano de 2014, ocorreram graves cortes orçamentários na saúde e educação, e, principalmente em 2015, as bolsas de assistência estudantil foram sistematicamente reduzidas. Em função disso, os índices de retenção e evasão no ESR crescem, pois, o estudante de fora da cidade não tem como se manter, pagar aluguel, alimentação, transporte, etc. 
Mancebo et al (2016) fizeram uma análise das crises econômica e política que passa o país e se reflete nas universidades públicas:

Nas instituições de educação superior públicas, o movimento de expansão de matrículas e cursos - como foi o caso do Reuni -, verificado pelo menos até 2013, é refreado em função dos ajustes, deixando às instituições a amarga tarefa de reconfigurar diversos procedimentos internos, para fazer frente à expansão (do período anterior) que lhes legou mais alunos, cursos, campi e forte interiorização, sem o devido financiamento. (p. 212)

Os estudantes que residem na cidade de Campos também evadem por questões financeiras, por não conseguir conciliar a jornada de trabalho com outras atividades e acompanhar os trabalhos acadêmicos e de avaliação das disciplinas oferecidas. Outros desistem por dificuldade de aprendizagem e sentem-se envergonhados por estar no ensino superior e não compreender as explicações do professor ou por apresentar dificuldades na interpretação de textos acadêmicos.

Hoje, o desafio maior da UFF e do ESR é o de cumprir a meta de redução dos índices de evasão e de retenção de estudantes, pois com o modelo de gestão de gerenciamento, atingir a meta significa obter resultados positivos na avaliação e, com isso, ampliar o orçamento da universidade. Isto poderá ser uma luz no fim do túnel para realização de concurso público para o quadro docente, bem como a ampliação das bolsas de assistência estudantil, além da melhoria no âmbito da infra-estrutura do campus.

\section{Considerações finais}

A partir da breve exposição, não se pode negar que o Reuni ampliou o acesso ao ensino superior nas universidades federais, assim como o Prouni elevou o número de matrículas nas instituições privadas de ensino superior. O programa Reuni garantiu o acesso de setores historicamente excluídos das universidades federais, porém, não garantiu a permanência desses estudantes. É o que se evidencia no campus da UFF em Campos, os índices de evasão aumentando a cada dia, pois acesso e permanência deve fazer parte de uma política integrada para efetivamente democratizar o ensino superior.

$O$ fato é que um docente ponderou em seu discurso no Colegiado de Unidade ${ }^{13}$ que aprovou a adesão do ESR ao Reuni que: "se o governo tem verba, então as repasse para que possamos discutir de forma autônoma como aplicá-las". Entretanto, o mesmo programa revelou-se uma modalidade de política educacional que submeteu às universidades federais a um termo de adesão com prazo estipulado de cinco anos para cumprir as metas quantitativas ${ }^{14}$ do Reuni, e como recompensa ganhar $20 \%$ de custeio de investimentos públicos - ou enquanto a União tivesse verba - pois não especificou em sua redação a fonte desse dinheiro para o programa?

Enfim, a expansão para o setor privado continua sendo uma fonte de lucro a nível internacional, pois o predomínio da educação como um serviço é o que predomina no modelo neoliberal. Para as universidades federais o legado do Reuni vem sendo o do vazio financeiro, além de docentes sobrecarregados com o ensino, sem tempo de

${ }^{13}$ Conforme redação da ata de 10 de outubro de 2007.

${ }^{14}$ Aumentar as taxas de conclusão dos cursos de graduação presencial para $90 \%$ e o número de alunos por professor 18 por 1.

Regae: Rev. Gest. Aval. Educ.

Santa Maria

v. 7

ก. 16

Set./dez., 2018

p. $91-110$ 
produzir pesquisa, salas de aula com 80, 90 alunos, sem qualidade na aprendizagem, ausência de técnicos para dar suporte aos docentes e estudantes e, obras inacabadas, que vêm se deteriorando com o tempo. Portanto, urge que a comunidade acadêmica realize uma reflexão acerca do papel da universidade pública como vetor de democratização do conhecimento e de desenvolvimento regional, porém, questione, sobretudo, qual o modelo educacional vem sendo oferecido à classe trabalhadora nesse contexto, e quais as possibilidades que esse modelo vem oferecendo para a emancipação desse setor.

\section{Referências}

AMARAL, Nelson Cardoso. Avaliação e financiamento de instituições de educação superior: uma comparação dos governos FHC e Lula. Atos de Pesquisa em Educação, Rio Grande, v. 4, n. 3, 2009, p. 321-336.

BRASIL. Lei n. 10.172, de 9 de janeiro de 2001. Aprova o Plano Nacional de Educação (PNE). Diário Oficial da União, Brasília, 10 jan. 2001.

COMERLATTO, Luciana Paz; CAETANO, Maria Raquel. As parcerias público-privadas na educação brasileira e as decorrências na gestão da educação: o caso do Instituto Ayrton Senna. PERONI, Vera Maria Vidal (org.). Redefinições das fronteiras entre o público e o privado: implicações para a democratização da educação. Brasília: Líber Livro, 2013, p. 245-265.

DAVIES, Nicholas. O financiamento da educação estatal no Brasil: velhos e novos desafios. Rev. Bras. Pol. Adm. Educ., Brasília, v. 16, n. 2, 2000, p. 159-176.

DOURADO, Luiz Fernandes. Plano nacional de educação enquanto política de estado: antecedentes históricos, avaliação e perspectivas. In: DOURADO, Luiz Fernandes (org.). Plano nacional de educação (2011-2020): avaliação e perspectivas. Goiânia: UFG; Belo Horizonte: Autêntica, 2011, p. 17-59.

HARVEY, David. Condição pós-moderna. São Paulo: Loyola, 2008.

LIMA, Kátia. Contra-reforma na educação superior: de FHC a Lula. São Paulo: Xamã, 2007.

MANCEBO, Deise. MARTINS, Tânia Barbosa. VALE, Andréa Araujo do. Políticas de expansão da educação superior no Brasil: 1995-2010. Revista Brasileira de Educação, v. 20, n. 60, 2015, p. 31-50.

MANCEBO, Deise. JUNIOR, João dos Reis Silva. Expansão da educação superior e a reforma da rede federal de educação profissional. Revista Educação em Questão, Natal, v. 51 , n. 37,2015 , p. 73-94.

MANCEBO, Deise; SCHUGURENSKY, Daniel. A educação superior no Brasil diante da mundialização do capital. Educação em Revista, Belo Horizonte. v. 32, n. 0, 2016, p. 205225.

MONTAÑO, Carlos (org.). O canto da sereia: crítica à ideologia e aos projetos do terceiro setor. São Paulo: Cortez, 2014, p. 19 a 95.

NEVES, Lúcia Maria Wanderley (org.). O empresariamento da educação: novos contornos do ensino superior no Brasil dos anos 1990. São Paulo: Xamã, 2002. 
NEVES, Lúcia Maria Wanderley. Por que dois planos nacionais de educação? In: NEVES, Lúcia Maria Wanderley. Educação e política no limiar do século XXI. Campinas: Autores Associados, 2008, p. 147-182.

PAULA, Cristiana Maria de. Neoliberalismo e reestruturação da educação superior no brasil: o REUNI como estratégia do governo Lula e da burguesia brasileira para subordinar a universidade federal à lógica do atual estágio de acumulação do capital. Niterói: UFF, 2009. 246f. Dissertação (mestrado em Educação). Universidade Federal Fluminense.

PEREIRA, Luiz Carlos Bresser. A crise da América Latina: Consenso de Washington ou crise fiscal? Pesquisa e Planejamento Econômico, v. 21, n. 1, 1991, p. 3-23.

PERONI, Vera Maria Vidal. Redefinições das fronteiras entre o público e o privado: implicações para a democratização da educação. Brasília: Liber Livro, 2013.

PERONI, Vera Maria Vidal. Política educacional e papel do estado no Brasil dos anos 1990. São Paulo: Xamã, 2003.

REIS, Luiz Fernando. Dívida pública, política econômica e o financiamento das universidades federais nos governos Lula e Dilma (2003-2014). Universidade e Sociedade, Brasília, v. 57, 2016, p. 16-35.

SAVIANI, Demerval. A expansão do ensino superior no brasil: mudanças e continuidades. Poíesis Pedagógica, v. 8, n. 2, 2010, p. 4-17.

SAVIANI, Demerval. Plano de desenvolvimento da educação. São Paulo: Autores Associados, 2009.

SILVA, Ilse Gomes. A reforma do estado brasileiro nos anos 90: processos e contradições. CONGRESSO PORTUGUÊS DE SOCIOLOGIA, 4, 2000. Anais ... Coimbra: UC, 2000, p. 1-13.

QUEIROZ, Viviane. Fundo de financiamento estudantil - Fies: uma nova versão do Creduc. Universidade e Sociedade, Brasília, v. 24, n. 55, 2015, p. 44-57.

Micheli Marques Borowsky é mestre em Políticas Sociais pela Universidade Estadual do Norte Fluminense Darcy Ribeiro e Pedagoga-área da Universidade Federal Fluminense, no Instituto de Ciências da Sociedade e Desenvolvimento Regional, na cidade de Campos dos Goytacazes.

Rua Barão de Miracema, 449 - 28030-361 - Campos dos Goytacazes - RJ - Brasil.

E-mail: micborowsky@yahoo.com.br.

Renata Maldonado da Silva é doutora em Educação pela Universidade Federal Fluminense, professora associada no Laboratório de Estudos da Educação e Linguagem da Universidade Estadual do Norte Fluminense Darcy Ribeiro e no Programa de Pós-Graduação em Políticas Sociais.

Rua Marechal Floriano, 222/402 - 28010-162 - Campos dos Goytacazes - RJ Brasil.

E-mail: r.maldonado@globo.com.

Recebido em 11 de março de 2018.

Aceito em 7 de junho de 2018.

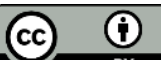

